\title{
La Sociedad de Fomento Fabril y los Desafíos de los años 30: entre la Turbulencia Política y el Liderazgo Gremial
}

\author{
Eduardo López Bravo* \\ UNIVERSIDAD DE SANTIAGO DE CHILE
}

\section{RESUMEN}

La primera mitad de la década de 1930 fue compleja para las elites económicas y las asociaciones empresariales. Los agudos problemas sociales, políticos y económicos desencadenados desde la Gran Depresión y la posterior caída del gobierno de Carlos Ibáńez del Campo repercutieron con fuerza en el mundo empresarial y sus tradicionales organizaciones. La vorágine de cambios de gobierno, la ampliación de las atribuciones estatales para promover el desarrollo económico, las instituciones de control de precios y la legislación social dan cuenta de la profundidad del cambio social y político que experimentó el país.

Este artículo analiza el proceso de reacción y rearticulación empresarial frente a un cuadro social y político adverso que culminó en la formación de la Confederación de la Producción y el Comercio (CPC). Nos interesa destacar que en el transcurso de los ańos treinta SOFOFA asumió crecientemente un liderazgo gremial que la posicionó como la asociación empresarial más activa en defensa de los intereses de los empresarios nacionales.

Palabras Clave: Empresarios, SOFOFA, CPC, fomento.

\section{Abstract}

The first half of the decade of 1930 was complex for economic elites and business associations. The acute social, political and economic problems triggered since the great depression and the subsequent fall of the Government of Carlos Ibánez del Campo passed with force in the business world and their traditional organizations. The maelstrom of changes of Government, the extension of the powers of the State to promote economic development, price control institutions and social legislation realize the depth of the social and political changes experienced by the country.

This article discusses the process of reaction and rearticulation business facing an adverse social and political picture which culminated in the formation of the Confederation of production and Commerce (CPC). We want to emphasize that in the course of the 1930s SOFOFA increasingly took a Union leadership that positioned her as the most active business association in defense of the interests of domestic entrepreneurs.

Keywords: Businessmen, SOFOFA, CPC, promotion.

* eduardolopezb@yahoo.es 
INTRODUCCIÓN: EL PROBLEMA GLOBAL

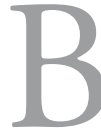

en Ross Schneider argumenta que cuando se organiza, el sector privado está esencialmente reaccionando a las acciones gubernamentales ${ }^{1}$. Nuestro argumento es que ese es también el caso cuando intenta optimizar sus capacidades organizativas y políticas para hacer frente a lo que percibe como escenarios de amenaza e incertidumbre. En el caso chileno, las repercusiones de la depresión económica de comienzos de los años 30 y el ciclo político que se instaló con la caída de Carlos Ibáńez demostraron a las fuerzas de la producción en su conjunto que el país no sólo se encaminaba a un proceso de cambios políticos y sociales contrario a sus intereses, sino que, y como advierte Genaro Arriagada, a un tiempo político y social que fue experimentado como el "primer gran miedo empresarial"2.

Desde la crisis económica desencadenada por la Gran Depresión y la caída del gobierno de Carlos Ibáñez del Campo el país asistió a una vorágine de transformaciones que incluyeron el advenimiento de la República Socialista, la creación del Comisariato de Subsistencias y Precios, la vigencia del nuevo Código del Trabajo y el surgimiento de las Milicias Republicanas, por mencionar algunos eventos. Todos estos acontecimientos dan cuenta de la profundidad del cambio social y político que experimentó el país. Lo que ocurrió entre 1929 y 1932 fue tan simple como complejo: El país asistió a un interregno donde la política quedó dislocada de la sociedad, con escasa capacidad para influir y conducir los procesos económicos y sociales $^{3}$.

En un cuadro social y político adverso las asociaciones patronales pusieron énfasis en la rearticulación y consolidación de sus organizaciones $y$, por otra parte, colaboraron con el intervencionismo y los diferentes ensayos de fomento productivo estatal $^{4}$. En efecto, en la primera mitad de la década de 1930, la Sociedad de Fomento Fabril (SOFOFA) participó activamente en la convocatoria realizada por la Sociedad Nacional de Agricultura (SNA) para la formación de un Comité General de Sociedades en octubre de 1931. Asimismo, elaboró un Plan de Fomento de la Producción 
en mayo de 1932 en que actualizaron sus planteamientos en materia de fomento productivo 5 . Por último, las fuerzas patronales consolidaron un proceso de restructuración organizacional que significó la incorporación de nuevos socios y el reemplazo paulatino de los dirigentes tradicionales ${ }^{6}$.

La coyuntura que cerró la caída de la República Socialista y la nueva etapa que abrió la segunda experiencia presidencial de Arturo Alessandri Palma en 1932 condujo a las fuerzas de la producción a una profunda reflexión respecto al sistema político y económico que se instalaba en el país. El retorno a la normalidad política mostró a las asociaciones patronales un rostro social y político con clara inclinaciones de centroizquierda y que se presentaban hostiles a las clases altas y a los intereses empresariales. Las condiciones económicas en el último tercio de 1932 no fueron las mejores. La producción nacional, el empleo y los salarios seguían bajando; el volumen de las exportaciones tocó sus índices más bajos y el costo de la vida experimentó las fluctuaciones más significativas desde el año 1919. La inflación casi se duplicó durante todo este año, alcanzando el 23,64\% (Ver gráfica 1) ${ }^{7}$.

En definitiva, las asociaciones patronales adoptaron la opción de unir fuerzas en la defensa de sus intereses y hacer frente al cuestionamiento de los pilares de la actividad privada; vale decir, la amenaza al derecho de propiedad, la seguridad jurídica, la libertad económica y el sistema de autoridad en la empresa ${ }^{8}$. Esto último es lo que va a ocurrir entre 1932 y 1934 , cuando para enfrentar un escenario de amenaza se propusieron organizar la Confederación de la Producción y el Comercio (CPC). 
Gráfico 1. Índice de Precios al CONSUMidor. VARIACIÓN ANUAL, I929 - I945

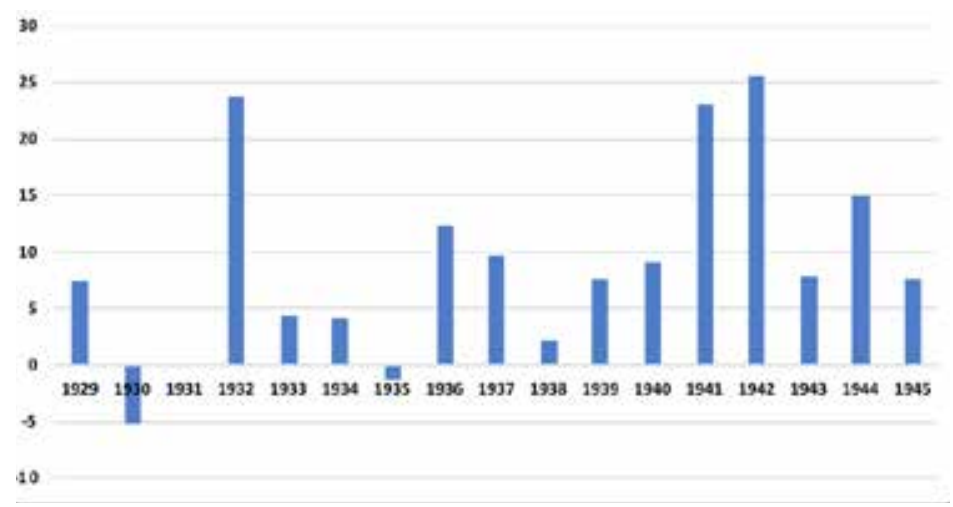

Fuente: Díaz, José, Lüders, Rolf y Wagner, Gert, Chile 1810 - 2010. La República en cifras. Historical Statistics. Ediciones Universidad Católica de Chile. Santiago, 2016. p. 374; Díaz, José y Wagner, Gert, Inflación y tipo de cambio:

Chile 1810 - 2005, Documento de trabajo No XXX, 2008, pp. $51-52$.

Respecto a la formación de la CPC existen algunas interpretaciones necesarias de considerar. Para algunos autores, la creación de una entidad que agrupara a las cuatro principales asociaciones empresariales debe entenderse en el contexto de una fase de institucionalización no sólo de los partidos políticos, sino que también de los grupos de interés del mundo del trabajo y el capital' Para otros trabajos, la CPC tuvo como objetivo convertirse en una plataforma instrumental capaz de enfrentar el creciente poder del movimiento sindical, influir en el aparato estatal y estimular a los partidos de clase alta a renovar sus organización interna y propuestas programáticas ${ }^{10}$. Desde una mirada analítica de las ciencias políticas, se argumentó que la CPC constituyó una reacción a la ineficacia de los partidos tradicionales - liberales y conservadores - para defender el mundo empresarial, los derechos de propiedad y el orden social ${ }^{11}$. En la misma línea interpretativa, el texto "Chile, 100 años de industria", editado por la SOFOFA con motivo del centenario de la fundación de la entidad gremial, sostiene que las asociaciones patronales conformaron la nueva federación con el objetivo que 
los partidos históricos podrían evolucionar en su organización y actualizar sus programas frente a las nuevas necesidades económicas y sociales del país ${ }^{12}$. Más recientemente, Gabriel Salazar ha sostenido que la conformación de la CPC fue una reacción de los empresarios propiamente industriales contra objetivos económicos que promovía el Ministro de Hacienda Gustavo Ross Santa María, quien privilegió las razones del Fisco por sobre las políticas de fomento industrial. Se trató, por tanto, de un camino complejo y audaz de presión sobre y/o contra el Estado ${ }^{13}$.

Sin tratarse de tesis erróneas, estas perspectivas analíticas deben ser complementadas, pues ellas no consideran en toda su dimensión el comportamiento político de las asociaciones empresariales y las relaciones con el Estado y la política de tal crucial coyuntura. En este artículo sostenemos que cuando las cuatro grandes asociaciones empresariales, a saber, la SNA; la SOFOFA; la Cámara Central de Comercio (CCC) y la Sociedad Nacional de Minería (SONAMI) se proponen fundar la $\mathrm{CPC}$ lo hacen por tres motivos fundamentales: a) hacer frente al radicalismo del movimiento sindical y los retos de la aplicación de la legislación laboral; b) desplegar una estrategia de coordinación empresarial de corte corporativista frente al gobierno de Arturo Alessandri y el incipiente Estado desarrollista; y c) posicionarse como un organismo paraguas permanente de los intereses empresariales en el naciente sistema democrático multipartidista.

Tan importante como lo anterior fue el papel que asumió la SOFOFA. En el marco de la reorganización de las asociaciones empresariales, el gremio industrial se transformó en el exponente más activo de las demandas de los empresarios nacionales. El liderazgo de la entidad industrial se debió a tres procesos que se desarrollaron de manera paralela. En primer lugar, si bien el desempeño de la actividad manufacturera durante la década de 1920 fue complejo, desde 1933 alcanzó un repunte sostenido en comparación con los signos de inestabilidad y vértigo de los sectores minero y agrícola (Ver gráfica 2). En segundo lugar, desde 1927 la importancia del sector manufacturero quedó plasmado en el tratamiento preferencial 
del conjunto de los programas económicos gubernamentales. Finalmente, los ańos treinta se caracterizaron por el progresivo ingreso de grandes empresarios a las filas de la SOFOFA, renovando la composición del Consejo Directivo. Para la década de 1940, más del doble del directorio se encontraba conformado por personas que tenían posiciones o participación en empresas agrícolas, comerciales y mineras ${ }^{14}$.

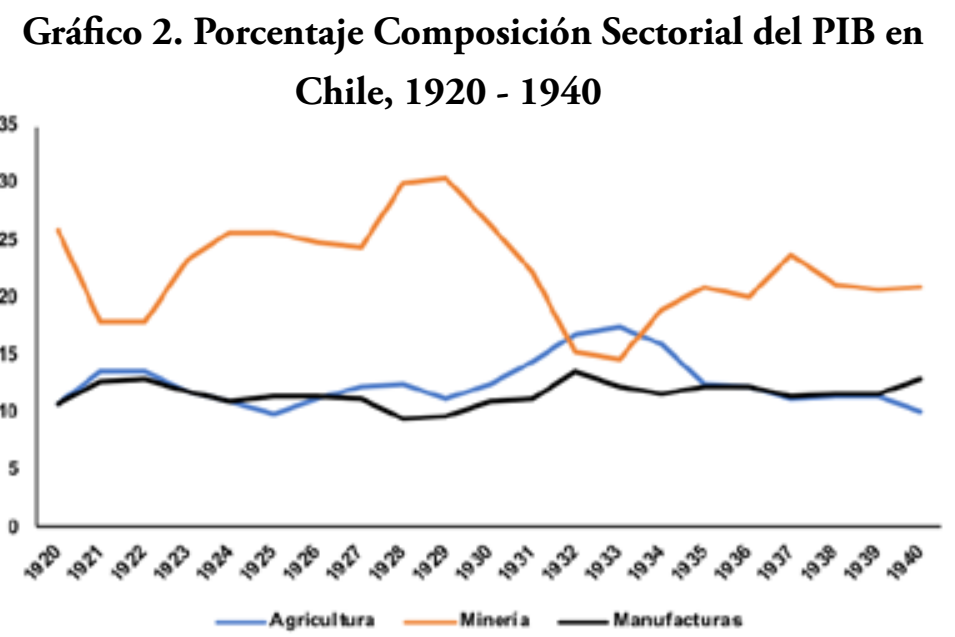

Fuente: José Díaz, Rolf Lüders y Gert Wagner. Chile 1810 - 2010. La República en cifras. Historical Statistics. Ediciones Universidad Católica de Chile. Santiago, 2016. pp. 746.

Desde una perspectiva metodológica, pocas veces los estudios sobre los empresarios y sus gremios consideran las condiciones -sociales, políticas y económicas- de largo y mediano aliento para ayudar a comprender el comportamiento político de los empresarios y sus asociaciones patronales. Asimismo, rara vez son analizados en la dimensión social de los problemas, es decir, como actores sociales colectivos e individuales que se relacionan con la sociedad y el Estado para elaborar respuestas políticas y programáticas frente a los desafíos que presenta alguna coyuntura específica. A pesar de los importantes avances de estas investigaciones, ninguno incursionó - y no era su propósito - en la trama interna de los gremios empresariales a través 
del estudio de los debates y discusiones en el seno de las entidades gremiales, lo cual puede contribuir a dilucidar ¿cuáles fueron las motivaciones para que un grupo de empresarios en base a sus organizaciones emprendieran distintos repertorios de acción política para defender sus intereses y, al mismo tiempo, incursionar en los debates acerca de la política económica y social del país?

Para redactar este trabajo hemos revisado fuentes documentales y periódicos. En relación a las primeras, están constituidas por las Actas del Consejo Directivo y las Juntas Generales de Socios de SOFOFA. Estas fueron publicadas en la revista gremial Boletin de la Sociedad de Fomento Fabril hasta el año 1934. Desde el mes de enero de 1935, la revista oficial del gremio industrial adoptó el nombre de "Industria". El períódico consultado fue El Mercurio. De esta manera, hemos podido reunir el material suficiente para reconstruir el proceso histórico que nos proponemos relatar.

DisLOCACIÓN DEL RÉGIMEN POLÍTICO, RESTRUCTURACIÓN DE LAS ASOCIACIONES EMPRESARIALES Y CONSOLIDACIÓN DEL LIDERAZGO GREMIAL DE LA SOFOFA.

Durante el período oligárquico, las élites económicas ejercieron influencia directa e indirecta mediante los contactos sociales y familiares que mantenían con líderes políticos, las autoridades de gobierno y parlamentarios por el sólo hecho de compartir un mundo social. Ejemplo de lo que comentamos es resumido por el estudio de Constantine Mengues, quien sostiene que la historia oficial del SNA sugiere que hasta la década de 1920 la mayoría de las leyes de política agraria fueron formuladas en la sede de la Sociedad Nacional Agrícola $^{15}$. En la medida que los años veinte evidenciaron una rápida ascensión de las clases medias, de los trabajadores urbanos, que se ampliaron las atribuciones económicas del Estado y se consolidó un nuevo aparato burocrático, esta capacidad de persuasión e influencia fue puesta en cuestión. Para afrontar las nuevas condiciones, las entidades gremiales debieron redefinir los mecanismos de influencia en el diseño de las políticas públicas mediante la consolidación de los mecanismos institucionalizados de consulta en el parlamento 
y el ejecutivo. Asimismo, cuando la irrupción de los militares en la década de los ańos treinta anunció la pérdida del control del poder político obligó a los empresarios a desplegar tácticas flexibles, pragmáticas y defensivas que incluían nuevos insumos y estrategias de persuasión empresarial. En este sentido, y como tendremos ocasión de revisar, en la escala de acción política patronal las convenciones y la conformación de asociaciones ejes como la CPC constituyeron las más altas expresiones de coordinación y organización empresarial en escenarios específicos de amenaza e incertidumbre.

Fueron tiempos difíciles para el liderazgo empresarial, lo cual incentivó su desafección con el clima político y económico, obligándolas a implementar relaciones con los poderes públicos que fueron restringiéndose en áreas de discusión específicas, a saber: el fomento productivo, el proteccionismo económico, los aumentos en la tributación y la legislación laboral. En momentos conflictivos los gremios empresariales mostraron una posición unificada a través de sus publicaciones oficiales y campañas de difusión, identificando los organismos públicos amigables y atacando selectivamente aquellas organizaciones o funcionarios que consideraron hostiles. Un claro ejemplo de estas prácticas defensiva lo constituyó el cuestionamiento al Comisariato de Precios y Subsistencias, las denuncias de sesgo de los supervisores de la Dirección del Trabajo y la aplicación del reglamento de higiene y seguridad en el trabajo.

En efecto, desde mediados de la década de 1920, el Estado chileno comenzó a expandir su radio de acción para dirigir la política económica, al mismo tiempo se transformó en arbitro de los conflictos laborales y agente de bienestar social. Para hacer frente al nuevo clima adverso, las asociaciones gremiales necesitaban refrendar su condición de legítimos representantes de los sectores empresariales. Con tal objetivo se ampliaron y restructuraron. Como hizo notar Sofía Correa, cada uno de los gremios empresariales - SNA, SOFOFA, SONAMI y la CCC - estableció un comité ejecutivo entre 5 a 10 miembros, un Consejo de alrededor de 60 a 100 consejeros y una Junta General de Socios que reunía a todos los asociados ${ }^{16}$. 
En el caso de la SOFOFA, Juan Eduardo Vargas observó que desde la década de 1920 el gremio industrial modificó progresivamente la composición de sus integrantes. Entre 1910 y 1920 el cuadro de consejeros no industriales disminuyó de un 65\% en 1910 hasta un $45 \%$ en 1928. Paralelamente se produjo la incorporación masiva de consejeros industriales que aumentó desde un 35\% en 1910 para llegar al 55\% en $1928^{17}$ (Ver Tabla No 1). Entre 1910 y 1920 el número de socios industriales pasó de 300 a cerca de 1.200.

Tabla 1. Consejeros sofofa en igio, I920 y I 928 en PORCENTAJES

\begin{tabular}{llll}
\hline \multicolumn{1}{c}{ Año } & 1910 & 1920 & 1928 \\
\hline Industriales & $35 \%$ & $40 \%$ & $55 \%$ \\
No industriales & $65 \%$ & $60 \%$ & $45 \%$ \\
\hline
\end{tabular}

Fuente: La Sociedad de Fomento Fabril, 1883 - 1928, Santiago, Imprenta Universidad Católica, 1976, p. 47

Como resultado del proceso descrito, desde mediados de la década los años veinte la hegemonía liberal en el Consejo Directivo de la SOFOFA comenzó paulatinamente a ser desplazada con la incorporación de nuevos consejeros que representaban a sectores empresariales directamente vinculados con las actividades productivas $y$, además, un segmento de profesionales de sectores medios que asumían un discurso proteccionista pro industrial de corte nacionalista. De esta manera, de los veinte miembros del Consejo Directivo electos para el período 1928 - 1930 destacaron las figuras de Francisco Antonio Encina ${ }^{18}$, Ramón Guillermo Subercaseaux Pérez ${ }^{19}$ y Juan Pablo Bennett Argandoña ${ }^{20}$. En este nuevo cuadro de agremiación, Guillermo Subercaseaux resultó una figura clave. Presidente de la entidad gremial durante el período 1925 y 1930 sus ideas influyeron en los planteamientos que la SOFOFA elaboró en la primera mitad de la década de 1930. Subercaseaux, postuló un programa económico donde el Estado estuviera ligado a los problemas económicos mediante la creación de una industria siderúrgica, la protección de la industria nacional a través del arancel 
aduanero, la rebaja de los derechos de internación para las materias primas industriales, fomento de la marina mercante, construcción de obras de regadío y ferrocarriles entre otras ${ }^{21}$.

La renovación organizacional de las asociaciones empresariales en los años treinta tuvieron como objetivo adecuarse a los complejos desafíos que enfrentaba el empresariado en general. En este esfuerzo de unificación de intereses SOFOFA participó activamente en la convocatoria realizada por la Sociedad Nacional de Agricultura (SNA) para la formación de un Comité General de Sociedades en octubre de 1931. Este primer intento de coordinación empresarial fue una respuesta a las graves circunstancias comerciales, monetarias y financieras desencadenadas por la aguda crisis económica de 1931 y la caída del gobierno del General Carlos Ibánez del Campo en julio de ese año obligaron a desplegar el primer intento de coordinación empresarial. Aprovechando la convocatoria a reunión de las diferentes ramas de la producción realizada por la Mesa Directiva de la SNA, el recién incorporado consejero de la SOFOFA, el ingeniero civil Walter Müller ${ }^{22}$, informó en sesión del Consejo Directivo del gremio industrial que el encuentro "...habia demostrado la necesidad de constituir, a la mayor brevedad, un Comité Permanente formado por dos representantes de cada una de las corporaciones patronales..."23. Para tales efectos, los industriales designaron como sus representantes a los señores Luis Matte Larraín ${ }^{24}$ y Pedro Luis González.

Entre las medidas adoptadas por el Comité General de Sociedades se propuso "... solicitar al Gobierno que se postergue la vigencia del nuevo Código del Trabajo..." 25 . Posteriormente, el Comité en reunión con el presidente Juan esteban Montero aprovecho de entregar tres propuestas de superación de los problemas económicos que incluían un proyecto de emergencia para enfrentar el problema de la cesantía; la inconveniencia de la moratoria comercial y la necesidad de organizar el control de las importaciones ${ }^{26}$. La rápida organización de las asociaciones patronales tuvo como resultado la creación del Consejo de Economía Nacional en abril de 1932. La institución vino a resolver dos anhelos de los gremios empresariales: conformar un organismo técnico ajeno a las presiones de la política 
partidista y, en segundo lugar, consolidar proyectos en estudio de mejoramiento industrial y agrícola para enfrentar las consecuencias de la Gran Depresión y la crisis salitrera ${ }^{27}$. A pesar de su constitución bajo la coordinación de los Ministros de Fomento y Agricultura, la iniciativa no prosperó en el tiempo.

Un segundo momento de articulación se originó cuando el recién asumido vicepresidente de la SOFOFA, Walter Müller, dio cuenta al Consejo Directivo de la elaboración de un Plan de Industrialización "...destinado a organizar las finanzas del pais y que, más que para realizarlo en la forma que se propone, tiene por objeto provocar una discusión en la cual podría salir la idea que se llevaría a la práctica"28. La presentación del plan dejó en evidencia varios aspectos relevantes. En primer lugar, consistió en una iniciativa del vicepresidente de la SOFOFA que no contaba con un acuerdo previo. En segundo lugar, reveló el estado preliminar de la discusión sobre la asociación del sector gremial con el Estado para enfrentar la crisis de la industria. Finalmente, y estrechamente relacionado con lo anterior, un tema central fue el escaso consenso respecto de las fórmulas de financiamiento y el destino de los recursos.

Consecuente con la coyuntura de crisis económica, el Consejo Directivo de la SOFOFA abrió un interesante debate respecto a las mejores posibilidades de financiamiento del Plan de Industrialización. El vicepresidente Müller propuso originalmente que las nuevas fuentes de producción fueran financiadas con las reservas de oro existentes en el Banco Central. Para el consejero Carlos Aguirre Luco $^{29}$, las nuevas industrias debían financiarse con los fondos de los propios capitalistas y el Banco Central podría facilitar los dineros para la importación de maquinarias. Pablo $\mathrm{Krassa}^{30}$, se manifestó partidario que los préstamos del Banco Central a las nuevas industrias se materializaran mediante el Instituto de Crédito Industrial ${ }^{31}$. Frente a estas posiciones, en la sesión del consejo siguiente, Walter Müller corrigió el documento incorporando dos alternativas de financiamiento para la adquisición de maquinaria industrial. Por una parte, que el Instituto de Crédito Industrial facilitara la inversión de los préstamos en oro del Banco Central a las nuevas Industrias, y en 
una segunda opción, propiciar cambios de salitre por maquinaria para las nuevas industrias sin tocar las reservas del Banco Central ${ }^{32}$.

En definitiva, en mayo de 1932, la SOFOFA hizo público el documento bajo el título de "Plan de Fomento de la Producción". El Plan sintetizaba la propuesta del gremio empresarial frente a los efectos de la crisis mundial en el país

Es imperioso buscar remedios a esta situación. Muchos han sido estudiados, y algunos puestos en práctica están dando buenos resultados. El problema puede definirse en pocas líneas: exportar más y reemplazar artículos de importación por producción nacional. Para esto último tenemos materias primas o podemos producirlas, $y$ nos falta solamente crear los medios que nos permitan llevarlos a la práctica ${ }^{33}$.

El diagnóstico realizado por los industriales sobre la situación general del país apareció en momentos de creciente descontento social y político hacia la administración de Juan Esteban Montero. En efecto, el gobierno de unidad nacional que encabezaba Montero con su política de austeridad poco o nada había realizado para resolver los apremiantes efectos de la Gran Depresión. Como advierten Drake y Ellsworth, durante el año 1932 las condiciones económicas continuaron empeorando al punto que el empleo y las exportaciones cayeron en forma más pronunciada que en 1931. Por el contrario, el costo de la vida y, especialmente los precios de los productos de primera necesidad subieron vertiginosamente hasta mediados de $1932^{34}$.

En este marco, la SOFOFA concluyó que las posibilidades de venta de los productos mineros y agrícolas en el extranjero eran muy limitadas o nulas. De esta manera destacaron que "...en cuanto de ellas depende, mejorará cuando haya pasado la crisis que azota al mundo actualmente. Aún más, existe el peligro de que estas industrias reduzcan sus actividades por agotamiento de los créditos de que actualmente disfrutan" ${ }^{35}$. En el fondo, los empresarios industriales no sólo se propusieron establecer las escasas posibilidades de reactivación económica a través de las exportaciones de materias primas, sino 
que, además, que pudiera volver a ser el motor de la economía. La solución más efectiva, por tanto, se encontraba en la sustitución de importaciones.

La creación de una serie de industrias básicas, de preferencia con materia prima nacional, permitiría crear riqueza permanente en el país y arrancar de la miseria a los miles de nuestros conciudadanos que la situación de crisis mantiene en una desocupación forzada.

Ha sido un error de las administraciones anteriores el de endeudar al país para hacer preferentemente inversiones no reproductivas. Otra sería nuestra situación, aún en plena crisis, si siquiera una parte de los fondos provenientes de los empréstitos contratados se hubieran invertido en industrializar a nuestro país ${ }^{36}$.

Con esta declaración, los industriales posicionaron el fomento industrial ya no como una alternativa para enfrentar la Gran Depresión, sino que como una estrategia de desarrollo futuro para el país. Asimismo, la asociación entre desarrollo industrial y el mejoramiento de las condiciones de vida de los trabajadores consolidaba un discurso ideológico de nacionalismo económico que postuló la protección del consumo interno, el trabajo y la formación de capital en el mercado nacional.

El reemplazo de las exportaciones para la SOFOFA podría comenzar con el financiamiento de nuevas actividades industriales como el azúcar de betarraga, aceites, fabricación de cánamo, celulosa, vidrio plano, hilos de lana para paños peinados y substitutos de bencina. En este sentido, el texto planteaba que,

Algunas de ellas han sido objeto, en otra época y con otro valor de nuestra moneda, de estudios prolijos y han sido abandonadas. Las circunstancias actuales son tan radicalmente diferentes que ellas pueden llevarse a la práctica con éxito, interesado a los capitales y adquiriendo importancia nacional ${ }^{37}$. 
Cabe destacar que el Plan no proporcionó cifras sobre los índices de producción manufacturas existentes en el país y de las actividades industriales que recomendaba financiar. Tampoco esbozó montos estimativos que implicarían los eventuales ahorro en las cuentas nacionales con la sustitución de importaciones. En definitiva, la propuesta se limitó a subrayar a nivel discursivo, y sin mayores especificaciones, los potenciales efectos positivos del fomento a la industrialización. En este sentido, la SOFOFA consideró que,

Realizado todo este programa, y en plena producción la industria, el problema de la desocupación estaría resuelto en su forma más racional, y haríamos dado otro paso considerable para independizarnos del extranjero, creando bienestar y riqueza en nuestro propio país ${ }^{38}$.

A pesar de las condiciones y la posición marginal de las actividades industriales en el conjunto de los sectores económico del país, la sustitución de importaciones se convirtió crecientemente para la entidad gremial en una aspiración, en un "paradigma", para la resolución de los cada vez más acuciantes problemas económicos y sociales, y también, como parte de una nueva visión del crecimiento económico. En la Memoria Anual del año 1933, el Consejo Directivo de la Sociedad reiteró las demandas contenidas en el Plan de Fomento elaborado en mayo del año anterior,

Este Plan tuvo por principios fundamentales la necesidad, bien definida, de acrecentar la exportación y la de reemplazar el mayor número posible de artículos de importación por otros de producción nacional, como un medio práctico de contrarrestar los efectos del desequilibrio comercial, producido por la reducción tan considerable del mercado del salitre y del cobre, productos básicos de nuestras exportaciones ${ }^{39}$.

En todo caso, el movimiento cívico militar que emergió el 4 de junio de 1932 cambió el eje de discusión sobre los problemas económicos y sociales del país. La breve experiencia de la República Socialista tuvo una enorme repercusión tanto en la opinión pública 
como en las asociaciones patronales al relacionar las ideas de revolución social con las fuerzas armadas. Su programa promovió el rol activo del Estado y su carácter solidario en oposición al individualismo liberal. Apelando a un socialismo más moderado que radical, más bien de clase media que obrero, más radical en apariencia que en la realidad, puso más énfasis en la planificación estatal que en el conflicto de clases, abogando por la ayuda inmediata a los sectores populares y el reordenamiento técnico de la economía a través de líneas de tipo corporativistas. Entre las medidas más emblemáticas adoptadas por la Junta se encuentran la disposición a que la Caja de Crédito Popular devolviera a los empeñantes todos los artículos de uso doméstico que estuvieran en prenda; la obligación al Banco Central de otorgar créditos a los institutos de fomento productivo y la socialización de las industrias ${ }^{40}$.

La República Socialista dividió las opiniones al interior de la SOFOFA. Algunos socios y consejeros se mostraron contrarios a colaborar con las nuevas autoridades. Otros, por lo menos, estuvieron dispuestos a escuchar las propuestas de fomento productivo que promovía el gobierno provisorio. La invitación que realizó el Ministro de Fomento a la Sociedad para que sus integrantes pudieran integrarse como asesores a los diferentes Comités que asesorarían a la cartera fue la instancia que evidenció estas incomodidades.

El presidente de la SOFOFA, Camilo Carrasco Bascunán, en sesión del Consejo Directivo, señaló que por falta de tiempo debió excusarse de participar en el Comité que estudiaría el plan de industrialización, agregando que "...si esta actitud pudiera ser interpretada en forma que ocasionara alguna dificultad a la Sociedad, ponia a disposición del Consejo el Cargo de Presidente". Por su parte, el vicepresidente, Walter Müller, informó que había sido designado por el Ministerio para el Comité de estudio de los combustibles, expresando que "...no habia aceptado porque no deseaba colaborar al actual Gobierno" ${ }^{41}$. Finalizó su intervención renunciando también a su cargo.

Las opiniones y renuncias de la Mesa Directiva provocaron un interesante debate. En opinión del consejero Juan Bennett “...los 
representantes de la industria en el Consejo deberían no excusar su cooperación en defensa de los intereses industriales, sea cual fuere la politica general del Gobierno. Basado en este principio, él ha aceptado la designación del Ministerio para integrar el Comité de Financiamiento de la producción". En términos similares se expresó el consejero Pedro Luis González, quien anunció que había aceptado la nominación como miembro del Comité de Industrialización ${ }^{42}$.

Las controversias entre la Junta cívico militar y el gremio industrial continuaron con ocasión de los propósitos de socialización de las industrias, y específicamente, la posibilidad de control por parte del Gobierno de la Refinería de Azúcar de Vińa del Mar. La iniciativa generó alarma en el gremio empresarial, así como también en el conjunto de las fuerzas productivas del país. En la editorial del Boletín de la SOFOFA, los industriales manifestaron que la "... socialización de las actuales industrias, o sea, su adquisición por el Estado era un verdadero error económico" 43 . Tratando de adaptarse a las circunstancias e intentando minimizar el conflicto, el Consejo Directivo dirigió al Ministro de Fomento, Víctor Manuel Navarrete, una comunicación en término respetuosos que exponía la preocupación de los industriales frente a las políticas económicas que consideraron indecisas:

En efecto, la situación de incertidumbre como consecuencia de los propósitos de socialización no bien definidos todavía por el nuevo Gobierno no sólo es perjudicial para la marcha de la industria, sino también fundamento peligroso para el país mismo en las actuales circunstancias de depresión económica y de cesantía obrera, pues lo que interesa al país y a sus clases productoras es precisamente continuar con la actividad de hoy, aún intensificarla ${ }^{44}$.

Asimismo, la carta aprovechó de insinuar la conveniencia que el Estado dedicara sus esfuerzos y recursos disponibles a instalar industrias ausentes en el país. El problema del momento, desde la perspectiva de los industriales, es de producción y consumo. 
Para mejorar la situación de depresión económica en que se halla el país, es indispensable intensificar la producción nacional, y en este sentido la Sociedad de Fomento Fabril ha colaborado activamente sugiriendo ideas y proyectos concretos; pero, para la obtención de ese ideal de expansión económica, queda mucho por hacer, y su realización tendrá que ser por la fuerza de las circunstancias lenta, aunque firme ${ }^{45}$.

La respuesta del Ministro de Fomento no tardó en llegar. La comunicación intentó despejar las incertidumbres empresariales que generaban los planes de intervención estatal y reiterar los objetivos de la política económica de la Junta de Gobierno.

En consecuencia, el Gobierno antes de limitar la iniciativa y la acción de los capitales particulares, las estimulará señalándoles nuevos rumbos más de acuerdo con los intereses generales de la colectividad y a la vez, con su mayor beneficio para esos mismos objetivos.

A este respecto, me es grato citarle los conceptos expresados por el presidente de la Exema., Junta de Gobierno, señor Carlos Dávila, en su reciente manifiesto al país:

Una economía colectiva es posible en nuestro país simultáneamente con la privada. Deseamos conservar esta última en cuanto fuere compatible con los nuevos principios económicos y aún estimo que ella tiene más que ganar que perder con ella ${ }^{46}$.

Finalmente, el ministro Navarrete formuló una invitación a la SOFOFA a sumarse a las medidas de bienestar en oposición al individualismo liberal,

El Gobierno y el país tienen, en consecuencia, derecho a esperar el apoyo de la Sociedad de Fomento Fabril, ya que no puede creer el infrascrito que les alarme el enérgico propósito del Gobierno de terminar el individualismo a "outrance", para una socialización que significará el control inteligente con la participación de todos los técnicos ${ }^{47}$. 
En suma, los intentos de conciliación pronto se esfumaron. El proyecto de ley del Comisariato General de Subsistencias y Precios del 30 de agosto de 1932 terminaron por imponer una actitud de resistencia en las fuerzas de la producción. Considerada como una medida "draconiana" contra todos los sectores productivos del país, la editorial del Boletín de la SOFOFA realizó un inédito cuestionamiento a la iniciativa de ley en los siguientes términos:

La intervención excesiva e injustificada de la autoridad en forma de Comisariato o en cualquier otra forma, es manifiestamente perjudicial para la Economía Nacional: el socialismo de Estado da resultados positivos, mientras fomenta el trabajo y la producción; pero está llamado a fracasar y a desacreditarse desde el momento en que pretende intervenir en el mecanismo de la producción, creando una organización burocrática, costosa e inútil para dirigirla ${ }^{48}$.

La discusión del proyecto de decreto de ley del Comisariato provocó la reunión conjunta de los presidentes y vicepresidentes de las CCC y Central de Comercio de Valparaíso (CCV); la SNA, la SONAMI y la SOFOFA, quienes a través de un Memorándum conjunto se manifestaron oficialmente contrarios al sistema que se proyectaba implementar. En reunión del Consejo Directivo de la Sociedad, el consejero Guillermo Subercaseaux, se expresó en duros términos frente a la idea gubernamental, manifestando:

Este proyecto lesiona los legítimos intereses de los industriales, ya que el Estado se reserva el derecho de expropiar las fábricas; estimando que se ha ido muy lejos en esta materia, pues en ningún otro país, fuera de Rusia, se ha dictado una ley con facultades tan omnímodas y que contemple medidas tan trascendentales ${ }^{49}$.

El Comisariato de Subsistencias y Precios prosperó en el tiempo, pero, no el gobierno socialista. La versión de "socialismo" como capitalismo estatal que promovía Carlos Dávila concluyó en 
septiembre de $1932^{50}$. No obstante, los ecos de la experiencia socialista y del conjunto de medidas económicas y productivas que intentó aplicar se encontraban aún presentes en la memoria del gremio industrial en enero de 1933. Así por lo menos es posible de observar en recuento anual del Consejo Directivo de la SOFOFA:

Con motivo de las nuevas directivas que el Gobierno provisorio, iniciado en junio, se empeńó en introducir tanto en el orden social como en el económico, los industriales y manufactureros del país se sintieron profundamente alarmados con la situación de incertidumbre que tales propósitos de socialización vendría a crear a sus fábricas, aspiraciones que las estimaban no sólo perjudiciales para la marcha de las industrias, sino también profundamente peligrosas para el país mismo, especialmente en las actuales circunstancias de depresión económica y de cesantía obrera, pues lo que interesa al país y a sus clases productoras es precisamente la intensificación de las actividades de hoy ${ }^{51}$.

La coyuntura que cerró la caída de la República Socialista y la nueva etapa que abrió la segunda experiencia presidencial de Arturo Alessandri Palma en 1932 condujo a las fuerzas de la producción a una profunda reflexión respecto al sistema político y económico que se instalaba en el país. El retorno a la normalidad política mostró a las asociaciones patronales un rostro social y político con clara inclinaciones de centroizquierda, en la que proliferaban un conjunto de partidos políticos que desafiaban a las instituciones tradicionales y se presentaban hostiles a las clases altas y a los intereses empresariales. En todos los casos de coordinación empresarial, SOFOFA asumió crecientemente la defensa de los intereses de los empresarios nacionales, elaborando propuestas, demandas y observaciones a las políticas de desarrollo económico que emanaban de las agencias de desarrollo económico estatales. 
RETORNO A LA NORMALIDAD POLÍTICA Y ORGANIZACIÓN DE LA CPC: COHESIÓN EMPRESARIAL Y DERROTA CORPORATIVA.

El segundo gobierno de Arturo Alessandri Palma logró al finalizar su período de seis años instalar un modelo de restauración capitalista que consiguió el retorno de los militares a los cuarteles y reactivar la economía nacional ${ }^{52}$. En base a un programa económico que consideró una profunda reforma tributaria, la renegociación de la deuda externa y la austeridad fiscal alcanzó una cierta recuperación económica mediante la aplicación de medidas de fomento sectorial encabezadas por el Estado que haciendo uso de créditos de fomento del Banco Central e incentivos tributarios consolidaron la tendencia proteccionista y de fuerte intervención estatal en la economía nacional. Sin duda la crisis del comercio exterior y el cierre de los mercados para las exportaciones nacionales consolidaron de manera pragmática la orientación de llamado "crecimiento hacia adentro" para evitar la dependencia externa ${ }^{53}$.

En el plano político, y como ha observado Marcelo Cavarozzi, la administración de Arturo Alessandri consolidó un rasgo esencial de las formas de hacer política para las siguientes décadas en el país: el personalismo político que actuó como una especie de ilusión de gestión política providencial, capaz de resolver los problemas sociales y económicos que los propios políticos generaban. De esta manera, Alessandri asumió el rol de articulador de arreglos bajo la mesa y de movimientos pendulares o contramarchas frente a medidas adoptadas y que caracterizaron la política chilena en las tres presidencias radicales que lo sucedieron en los siguientes años ${ }^{54}$. En tal sentido, Ricardo Donoso al describir el perfil político de Arturo Alessandri en 1932 destacó su rol reconstructor del sistema institucional derrumbado en los años de dislocación de la política:

En su afán de mantener el fervor de sus partidarios, a poco de asumir Alessandri por segunda vez la Presidencia de la República, acunó una frase, diciendo que era el mismo del año veinte... y que su programa estaba animado del mismo espíritu renovador... $\mathrm{Ni}$ desde el punto de vista político, ni del económico, 
ni del psicológico, había en esa afirmación nada de verdadero

Las viejas y manoseadas consignas del agitador del ano 20, la querida chusma y la canalla dorada, estaban ya relegadas al desvan d e los trastos inutiles, y el contumaz demoledor buscaria ahora la adhesion de las clases poseedoras, vistiendo la tunica del restaurador de las leyes y de la normalidad juridica ${ }^{55}$.

No obstante, los años de dislocación de la política frente a los problemas económicos y sociales de los años 1931 - 1932 generaron en el empresariado un cuadro de incertidumbre que ni el aparente retorno a la normalidad política con Arturo Alessandri logró morigerar. En este escenario, las asociaciones patronales adoptaron la opción de unir fuerzas en la defensa de sus intereses y hacer frente al cuestionamiento de los pilares de la actividad privada; vale decir, la amenaza al derecho de propiedad, la seguridad jurídica, la libertad económica y el sistema de autoridad en la empresa ${ }^{56}$.

El primer intento de cohesión empresarial lo constituyó la formación de la "Unión Patronal de Chile" en octubre de 1932. La nueva asociación de los gremios empresariales se planteó como objetivos "... agrupar los diversos sindicatos patronales y contribuir a la formación de estos mediante el estudio de la industria y el comercio en relación con las leyes sociales, régimen tributario, cuestiones económicas..." 57 . Las finalidades esgrimidas por la nueva entidad gremial generaron cierta controversia al interior de la SOFOFA, pues algunos consejeros consideraron que sus finalidades podrían rivalizar con las asociaciones patronales existentes. A pesar de lo anterior, algunos tuvieron en cuenta que la iniciativa constituía un primer paso en la unión del conjunto de las fuerzas de la producción frente al complejo escenario político y social. Así lo reconoció Walter Müller, quien manifestó que "... ante todo debería propenderse a la unión de los patrones de industrias similares, unión cuya falta se hace sentir y que era conveniente hacer una campaña en este sentido, para que se manifestara en forma más efectiva la defensa de los intereses patronales" 58 . 
Posteriormente, la nueva entidad adoptó el nombre de "Unión Patronal de la Industria y del Comercio", enfocando sus actividades de defensa gremial fundamentalmente a la esfera de la opinión pública. Sin embargo, y desde su origen, la mayor dificultad de la entidad fue la escaza representatividad del mundo empresarial. En efecto, hacia el año 1935, poco más de 600 fueron los socios e instituciones que la conformaban ${ }^{59}$.

Un segundo momento de articulación empresarial se verificó al tercer mes de la nueva gestión de Arturo Alessandri. El gobierno se propuso aplicar un programa de reactivación de la economía a través de una profunda reforma tributaria. La discusión tributaria se instaló, además, en momentos en que los empresarios se encontraban aún divididos respecto del papel del Estado en la economía. Para algunos la participación estatal debía limitarse al fomento de las industrias, mientras que otros eran partidarios que interviniera en forma directa como empresarios ${ }^{60}$.

Si bien las relaciones entre el Gobierno y los industriales habían comenzado auspiciosamente con los nombramientos en el Banco Central de Chile de Guillermo Subercaseaux, como presidente, y Luis Matte Larraín, como consejero, el clima varió sustancialmente con la propuesta de nuevos impuestos a las empresas para financiar la reactivación económica. Del malestar con la propuesta dan cuenta los órganos oficiales de las asociaciones patronales, sus actas y editoriales, particularmente, los debates en el Consejo Directivo de la SOFOFA. Paradojalmente, quien primero alzó su voz crítica fue Luis Matte Larraín, quien manifestó al interior del Consejo del gremio industrial que con la medida que se proyecta "...sólo se conseguirá el desistimiento de los hombres de empresa que intenten realizar la instalación de alguna industria" 1 .

En la primera semana del mes de marzo de 1933, el presidente del Consejo Directivo de la Sociedad, Camilo Carrasco Bascuñán, convocó a una sesión especial para tratar la situación de las industrias ante el proyecto de nuevos impuestos. La urgencia de la reunión fue argumentada en los siguientes términos:

Numerosos señores socios se han dirigido al Consejo 
verbalmente o por escrito, profundamente alarmados ante el excesivo rigor de la tributación propuesta, la que va a gravitar principalmente sobre las industrias, a anular sus esfuerzos, a arrebatarles sus legítimas utilidades, o aun a obligarlas a cerrar sus puertas en aquellos casos en que, por falta de un detenido estudio, resulte que las cargas igualan o sobrepasan a los beneficios ${ }^{62}$.

El proyecto originó una intensa campaña de persuasión de los socios de la SOFOFA durante los meses de marzo y abril en las Comisiones de Hacienda de ambas cámaras del Congreso, presentando observaciones a los siguientes ámbitos del proyecto: el aumento del 2\% sobre el monto de las operaciones; el impuesto extraordinario a los beneficios excepcionales; el impuesto a la perfumería; el impuesto a los cigarrillos y fósforos y el impuesto de cinco mil pesos que grava a las empresas con capital superior a un millón de pesos $^{63}$.

Apelando a un discurso de nacionalismo económico proteccionista, el Consejo Directivo de la SOFOFA argumentó "...la inconveniencia de estos impuestos en circunstancias en que debe fomentarse la producción nacional como un medio de independizarse del extranjero y, a la vez, para concluir, o, por lo menos, reducir la cesantía" ". Asimismo, insistieron que en su mayoría los gravámenes presentados afectarían negativamente el consumo y condiciones de vida de las clases populares. Concluyeron que las medidas que se pretendían imponer no contaban con la opinión de los industriales y que estarían en disposición de aceptarlas mientras “.... sean soportables y que se les deje una parte razonable de utilidades y no los obliguen a lanzar a la desocupación a todo o a una parte de su personal'65.

En la medida que las acciones de influencia directa en el parlamento comenzaban a mostrar resultados, el Consejo Directivo de SOFOFA fue moderando sus posiciones más beligerantes. En este sentido, Luis Matte Larraín fue un exponente de este cambio de posición al manifestar que "... ahora que el Gobierno se halla en una posición dificil, es justo que exija un sacrificio de los que están en situación de hacerlo". Terminó señalando: 
...si los industriales resisten toda nueva contribución, el Gobierno deberá recurrir a un empréstito interno o a emisiones de papel moneda, lo que precipitaría el país a un caos. De manera que se impone hacer un sacrificio en proporción a nuestros recursos. En todo caso, estos nuevos impuestos no alterarán el porvenir de la industria ${ }^{66}$.

En definitiva, la mayoría de las observaciones formuladas sobre el proyecto de nuevos tributos fueron atendidas por las Cámaras Legislativas y alcanzaron a ser incluidas en la Ley No 5154 del 10 de abril de 1933. Con este logro, los consejeros de la SOFOFA pusieron a prueba toda su capacidad de influencia como grupo organizado de presión en el sistema político y tuvieron que reconocer y cotejar el divorcio que comenzaba a operar entre los que detentaban el poder del Estado y la defensa de los intereses empresariales.

Un tercer momento de rearticulación empresarial lo constituyó la formación de la CPC entre los meses de abril y junio de 1934. Como se ha destacado anteriormente, desde la Gran Depresión las asociaciones patronales, y especialmente la SOFOFA, pusieron énfasis en la consolidación interna de sus organizaciones y, por otra parte, colaboraron con el intervencionismo y los diferentes ensayos de fomento productivo estatal ${ }^{67}$. Sin embargo, las cuatro grandes asociaciones empresariales sintieron que era necesario unir fuerzas y fundar la CPC para enfrentar movimiento sindical y los retos de la aplicación de la legislación laboral; desplegar una estrategia de coordinación empresarial frente al gobierno de Arturo Alessandri y organizar un organismo paraguas permanente de los intereses empresariales en el naciente sistema democrático multipartidista. El itinerario de constitución de la CPC contó con el liderazgo del gremio industrial. Con motivo de la celebración del cincuentenario de la fundación de la SOFOFA, Walter Müller, destacó la conveniencia de la organización unificada de las asociaciones empresariales.

Sólo una institución muy grande podrá defender debidamente los cuantiosos intereses invertidos en la 
industria nacional.

Como ejemplo de lo que puede y debe llegar a ser, me permito citar el de la Unión Industrial Argentina. Allende de los Andes, los industriales no han formado tienda aparte creando asociaciones gremiales independientes, que significan división de fuerza y debilitamiento consiguiente de la acción. Se ha cobijado todas bajo el mismo techo de una poderosa institución.

Dejo lanzada esta idea, ruego a los presentes que la consideren con benevolencia y que me acompañen con la imaginación a ver realizados los anhelos de una institución más grande, económicamente más fuerte y de más influencia... ${ }^{68}$

La invitación a la unidad empresarial que realizó Müller fue una crítica directa a los gremios empresariales que optaban por estrategias independientes frente al gobierno y el aparato público. Sin embargo, también fueron una convocatoria a consolidar a la entidad industrial como articuladora de la élite económica chilena. Posteriormente, Müller tendría la oportunidad de precisar en sesión del Consejo Directivo su opinión sobre la entidad argentina. Desde su perspectiva, la SOFOFA requería actualizarse y adaptarse a las actuales condiciones del momento mediante un fortalecimiento de su organización.

...sería necesario dar más vida a la Sociedad, hacer de ella una institución más sólida, a semejanza de la Unión Industrial Argentina, la cual, a pesar de que la industria argentina, en proporción, se halla menos desarrollada que la nuestra, constituye, sin embargo, una organización económicamente fuerte, pues tiene un hermoso edificio propio en pleno centro de Buenos Aires, están afiliados a ella todos los gremios industriales, cuenta con consultorio jurídico y comercial y otros servicios para sus socios ${ }^{69}$. 
Una opinión diferente expresó Luis Matte Larraín, ...es preciso no olvidar que la Sociedad de Fomento fabril tiene una tradición respetable que de ninguna manera conviene perder, como sería transformándola en una organización exclusivamente de defensa. La Sociedad se ha mantenido hasta ahora en un plano superior, pues para ella, ante que los intereses personales o gremiales, están los intereses generales, y esta circunstancia ha hecho que los Poderes Públicos la oigan y la consulten en toda ocasión ${ }^{70}$.

En este escenario, durante el mes de noviembre de 1933 se organizaron las reuniones del "Comité de Instituciones Patronales". La instancia incluyó a delegados de la SOFOFA, SNA, la Cámara Nacional de Comercio, La CCC, la Asociación Patronal Chilena del Trabajo y algunas otras instituciones. La SONAMI adoptó el acuerdo de no integrarse inicialmente al comité argumentando que el carácter combativo de la entidad contra la legislación laboral afectaría las buenas relaciones entre patrones y trabajadores en el sector minero. La abstención del empresariado minero podría interpretarse como un síntoma de fisuras o intereses diferentes en el conjunto de las asociaciones patronales para enfrentar los desafíos de los cambios políticos y sociales. Sin embargo, sólo representaron matices que no deben confundirnos.

Al finalizar el año 1933 existió el interés transversal en las fuerzas de la producción por la unidad empresarial mediante una estructura organizacional más amplia. Esta aspiración, que como revisáramos se venía gestando desde el restablecimiento del sistema político institucional, alcanzó maduración en los meses de abril y mayo del año 1934 con la formación de la "Confederación de Productores y Comerciantes" y cuya primera medida fue la convocatoria de la "Convención Gremial de la Producción y del Comercio". En su primer mensaje a la opinión pública, la nueva entidad supra-patronal expuso que los partidos políticos históricos habían perdido disciplina, cohesión e influencia. En estas condiciones, las diferentes ramas 
de la producción y el comercio se vieron forzadas a organizar un frente común capaz de hacer frente a lo que consideraron "...una abundante y poco atinada legislación tributaria y social' ${ }^{71}$.

La Convención gremial, reunida en Santiago entre el 10 al 14 de junio de 1934, contó con la participación de los representantes de la agricultura, la minería, industrias fabriles, del comercio mayoristas y minoristas, la Asociación Patronal Chilena del Trabajo y de las empresas de transporte marítimos y terrestres expresando la unidad de los diferentes gremios del país. El evento se organizó como una asamblea constituyente sectorial, confirmando no sólo la interconexión del empresariado como grupo de interés, sino que, además, la unidad y defensa contra lo que consideraron una severa amenaza a la propiedad, la libertad, el derecho a producir y el comercio. Por tanto, no fue extrańo que los principales temas de discusión fueran a) La intervención del Estado en las industrias particulares; b) El régimen tributario y c) La legislación laboral. De acuerdo con la editorial del Boletín de la SOFOFA, los diferentes productores y comerciantes no se oponen a la legislación social existente y tampoco proponen su derogación, su aspiración es que "... se la revise, con espiritu de equidad, en aquellas disposiciones que hoy causan constantes conflictos" 2 .

El Comité Organizador de la Convención estuvo compuesto por Jaime Larraín García-Moreno ${ }^{73}$, representante de la SNA, Carlos Hoerning, por la SOFOFA, Gastón Goyeneche, por la CCC y el asesor jurídico Jorge Rodríguez Merino. Asimismo, la participación incluyó en sus registros a grupos regionales, a las agencias promotoras de la economía y las grandes empresas del país. La sesión inaugural contó, además, con la asistencia del presidente Arturo Alessandri, y de los Ministros de Interior, de Hacienda, de Relaciones Exteriores y Fomento.

Los discursos de apertura por parte de las asociaciones gremiales estuvieron a cargo de Camilo Carrasco Bascuñán y Jaime Larraín García-Moreno. Un buen resumen del mensaje que intentaron instalar las entidades patronales lo expuso en tono enérgico el dirigente agrícola y posterior primer presidente de la Confederación multigremial Larraín García-Moreno: 
Las fuerzas de la producción y del comercio han clamado estérilmente durante largos años por la solución de sus problemas. Han esperado en vano que se acogieran sus demandas y estiman que ha llegado el momento en que deben hacerse escuchar. Con este fin se reúnen, por primera vez en la historia de nuestra República, y se disponen a emprender el camino que ha de llevarlas a pesar decisivamente en la vida del país. Hoy somos fuertes porque estamos organizados, mañana seremos invencibles, porque habremos mejorado nuestra organización ${ }^{74}$.

Concluida el evento multigremial, las fuerzas productoras difundieron a través de la prensa y los órganos oficiales década asociación patronal el "Manifiesto de la Confederación de la Producción $y$ del Comercio", documento a través del cual los líderes empresariales del país expresaban el consenso de la unificación gremial.

Duras experiencias nos llamaron a la unión; necesidades vitales nos obligan a permanecer en ella.

Los trastornos económicos, políticos y sociales de los últimos años han dańado gravemente la estabilidad del país, desmoralizando a los ciudadanos y creando una atmósfera de inequidad y desconfianza.

La subsistencia de este estado de cosas y la amenaza de su agravación, llevaron a los hombres de trabajo a definir sus responsabilidades y a abandonar la pasividad en que se habían mantenido ${ }^{75}$.

El Manifiesto, en una clara alusión a los trágicos acontecimientos ocurridos entre la última semana del mes de junio y la primera de julio del año 1934 en el fundo de Ránquil, expresó que debían “... terminar los intentos de subversión y anarquía que vienen sucediéndose desde hace años en el pais y que hoy arrecian en forma de poner en peligro los derechos más sagrados de la sociedad ${ }^{776}$. El aspecto más relevante del documento fue la propuesta de la Confederación patronal de crear el Consejo Nacional de Economía. Constituyó la idea matriz de 
la convención y una de las principales aspiraciones empresariales. Correspondió a Walter Müller exponer esta iniciativa,

Las entidades representativas de la producción y del comercio, de los empleados y obreros, deben hoy día limitar su acción a peticiones aisladas a los poderes públicos. Estas resultan, muchas veces, contradictorias, no han sido armonizadas dentro de un plan de conjunto, y raras veces consiguen ser oídas y tomadas en cuenta en la generación de nuestra legislación. Para evitar los defectos mencionados, creemos que se impone la creación inmediata por Decreto, y la posterior por Ley, de un Consejo Nacional de Economía, en que las fuerzas vivas del país tengan representación. ${ }^{77}$.

En esta nueva oportunidad, las asociaciones patronales aspiraron a la creación de una institución de rango ministerial que concediera a los empresarios "...el derecho a opinar, y a los Poderes Públicos, el deber de oír en todos los problemas que digan relación con la vida económica del pais"78. El Consejo, tal como fue presentado por Müller, debía integrar a 19 representantes de la industria, la banca, los trabajadores y los profesionales con explicita exclusión de los partidos políticos. Asimismo, solicitaron establecer una función de coordinación de tipo social corporativo que convocara a los "hombres más capacitados de las fuerzas productoras y comerciales del pais", bajo un diseño técnico y autónomo, ajeno a la participación de la política partidista y con iniciativa legislativa ${ }^{79}$.

Volvía a instalarse en los hombres de empresa la vieja aspiración que la política económica estatal y el desenvolvimiento cotidiano de la economía era un tema de especialistas, que exigía abordarse desde una institucionalidad técnica ajena a las presiones de los partidos políticos. Como señaló un representante de la SNA, en rigor "la gente no entiende las complejidades económicas de la mayoría de los problemas" ${ }^{80}$. Por tanto, las asociaciones patronales concluyeron que el edificio institucional que se consolidaba no debía estar organizada exclusivamente en lo político (para los políticos) sino 
que debía también estar constituido corporativamente (controlado por los actores productivos) y orientado hacia un proyecto nacional funcional con el desarrollo económico de fomento productivo ${ }^{81}$.

El rechazo a un Estado puramente político no significaba una vuelta al período oligárquico, por el contrario, las fuerzas de la producción asumían el cambio de época. El tema central en discusión eran los rasgos operativos del Estado para posibilitar el desarrollo de la producción. Las conclusiones de la Convención de la multigremial patronal apuntaban directamente a precisar las funciones estatales en las actividades económicas. Por ejemplo, se condenó la intromisión directa e indirecta del Estado en las actividades productivas de los particulares; se cuestionó que las inversiones de los fondos estatales (por organismos semifiscales y Cajas de Previsión Social) carecieran de una ley especial que evitará la competencia a la industria y el comercio y, por último, abogaron que el Estado reconociera a las asociaciones empresariales la acción orientadora, impulsora y reguladora de las actividades económica ${ }^{82}$.

Por eso consideraron que el establecimiento de un Consejo Nacional Económico encarnaría la razón económica a través del cual se institucionalizaría la intervención de los productores y comerciantes en la dirección económica del Estado. En opinión de las clases económicas reunidas en la Convención,

La necesidad de que las orientaciones de política económica del estado se determinen de acuerdo con bases prácticas y con el conocimiento de la realidad económico-social del país, evidencia lo indispensable que es la influencia en esta política de los elementos del capital y el trabajo, que están en contacto directo con la vida de los negocios, y de cuya experiencia y capacidad no puede prescindirse si se quiere dictar la legislación económica en forma segura y acertada ${ }^{83}$.

De acuerdo con lo anterior, el Consejo debía asumir un carácter eminentemente técnico, integrado mayoritariamente por las clases productoras "....sin base burocrática e independiente 
en su generación...” de las políticas económicas. ¿Quiénes serían esas clases productoras? En opinión de la CPC, los productores, los distribuidores y consumidores (los trabajadores). Un año más tarde, julio de 1935, Larraín García-Moreno tendría la oportunidad de profundizar en entrevista con El Mercurio la alianza socialcorporativista que consideró la multigremial:

El Estado moderno se mete en todo. No niego que debe encarrilar todo, supervigilarlo todo; es su misión. Pero, colocados en el extremo opuesto de un ayer liberal en que todo era "dejar hacer, dejar pasar", cae a veces el Estado moderno - y no es extraño - en extralimitaciones deplorables. Esto sucede en Chile, y mucho más en otros países. Los productores nos sentimos en este caso perjudicados. Y nos hemos asociado para hacer sentir el peso de nuestras razones. Nada más. No vamos contra el Estado; nadie lo necesita más que el productor. Tampoco vamos contra la vigilancia y la intromisión justa del Estado, muy eficaz a veces. Pretendemos, y no más, encausar la intromisión del Estado por senderos que a nadie dańen, más que al abusador y que a todos beneficien. $Y$ esto es tanto más necesario cuanto que los políticos no aciertan jamás en ese término medio ${ }^{84}$.

Cumpliendo los acuerdos de la Convención, la maesa directiva de la CPC envió al ejecutivo el 26 de julio de 1934 una propuesta bajo el título de "Proyecto de creación del Consejo de Economía Nacional'. En la exposición de motivos del documento, la suprapatronal aludió que tanto el individualismo y el socialismo como la libre iniciativa y del intervencionismo estatal han determinado “... la pugna constante de intereses, y otros la estagnación o el debilitamiento de las actividades creadoras de riqueza". En esta perspectiva:

Yerran evidentemente los que, buscando una solución a las contradicciones económicas y a la desarmonía de los intereses en juego, proponen una acción más directa del Estado. 
Es necesario adoptar soluciones que efectivamente lleven a la economía al orden, la estructura y el plan de que hoy carece. Y ellas sólo pueden encontrarse en la mancomunidad de las distintas actividades, en la coordinación de las directivas y en el estudio profundo y meditado de los problemas ${ }^{85}$.

Durante los meses de junio a octubre de 1934 las fuerzas de la producción y el Gobierno mantuvieron una prolongada relación epistolar referida al Consejo Nacional de Economía. En el marco de nota enviada por la CPC al Ejecutivo señalando sus diferencias por la continuidad de los impuestos extraordinarios para el financiamiento de los gastos fiscales para el año 1935, la Confederación aprovechó de recordar el envío de la propuesta del Consejo de Economía:

...aprovechamos la oportunidad para rogar a V. E., que el Gobierno tenga bien pronunciarse sobre el proyecto de Consejo de Economía Nacional que la Confederación de la Producción y del Comercio elevó al Ejecutivo hace algún tiempo. Este organismo podría autorizar la opinión directa de todos los sectores económicos y aportar un valioso concurso para la dirección de la política tributaria. Su acción sería aún más importante para elaborar un plan de fomento de la riqueza nacional, que complementara la labor financiera que solamente desarrolla el Ministro de Hacienda. Creemos que la buena disposición que V. E., ha manifestado a la Confederación de la Producción y del Comercio, es augurio de que el Consejo de Economía Nacional puede ser pronto una realidad... ${ }^{86}$

La respuesta de Alessandri no se hizo esperar. En misiva enviada a Larraín García-Moreno y la CPC, advirtió a la multigremial que:

$\mathrm{Ud}$., me pide que me pronuncie sobre el proyecto de creación del Consejo de Economía Nacional ... En vista de la nerviosidad de la nota que contesto, y atendida 
a la poca justicia que hay para juzgar los actos de la política nacional que desarrolla el actual Gobierno, he desistido, por ahora, de crear un organismo que no consulta la Constitución Política del Estado ni tampoco las leyes de la República.

Como se lo dije verbalmente, no sería tampoco aceptable la creación de un organismo como el que Ud., me proponía al cual se viera obligado el Gobierno a someter a su consideración todos los proyectos de carácter económico, antes que enviarlos al estudio y despacho de los organismos creados por la Constitución para dictar las leyes de la república. Eso importaría un tutelaje que estimo inconveniente e inaceptable ${ }^{87}$.

Mediante la carta de respuesta Alessandri, con todo el peso de la experiencia política y apelando a la restauración institucional, dejó en claro a los empresarios que “...las consideraciones de carácter general sólo incumben al Gobierno y los organismos creados por la Constitución". De esta manera, no sólo recordó a los empresarios sobre la inconstitucionalidad de la propuesta, sino que, además, los invitó a considerar al derecho de petición frente a las autoridades como el medio de canalización de sus demandas. Acusando el golpe del contenido de la misiva, la Confederación no tardó más de dos días en elaborar una réplica a la epístola presidencial.

Lamentamos que V. E., haya visto en nuestro memorial un espíritu animoso o destemplado y que él haya herido sus sentimientos en forma de determinar una resolución como la que expresa... El Consejo de Economía Nacional a juicio de la Confederación, es el único medio de vincular provechosa y permanentemente a las fuerzas de la producción y del comercio con los Poderes Públicos, ofreciendo a éstas la oportunidad de intervenir en el estudio de los problemas que con ella se relacionan. El derecho de petición es, sin duda, un camino para elevar el sentir de los ciudadanos hasta el Gobierno, 
pero no hay que olvidar que está condicionado por una serie de factores, que corresponden a circunstancias accidentales y que le restan la eficacia que tiene una colaboración continuada ${ }^{88}$.

La aceptación conceptuosa de las reglas del juego Constitucional por parte de las asociaciones empresariales alcanzó aparente éxito el 25 de octubre de 1934 cuando Arturo Alessandri mediante Decreto Ley 3.300 formalizó el Consejo Económico Nacional. Señalamos que es un éxito aparente, pues, en rigor el texto legal que creó el Consejo fue como el Ejecutivo entendió que debía materializarse. Revisemos tres aspectos medulares del proyecto ${ }^{89}$ :

1. El Consejo estará formado por cinco ministros correspondientes a los departamentos de Hacienda, Comercio, Fomento, Agricultura y Trabajo, que a su vez será asesorado por una comisión compuesta de diez representantes de la Confederación de la Producción y del Comercio y de nueve representantes de diversos organismos relacionados con las actividades económicas ${ }^{90}$.

2. El Consejo de Economía Nacional estará encargado de coordinar las iniciativas y procedimientos del Gobierno relacionadas con las actividades económicas y financieras del país.

3. La Comisión Asesora se reunirá a iniciativa del Consejo, a lo menos una vez al mes, y será oída en todos aquellos estudios $\mathrm{y}$ acuerdos que se relacionen con las actividades productoras y del comercio que el Consejo someta a su consideración.

En rigor, la iniciativa de las asociaciones empresariales topo con una contundente respuesta de rechazo por parte del edificio institucional que Arturo Alessandri en su versión restauradora intentaba imponer. En ese contexto, si la CPC proyectó que el nuevo Consejo Económico debía intervenir directamente en materia del diseño de la política económica, con autonomía técnica bajo control de la experiencia de las fuerzas productoras y sin la dirección de la clase política, el presidente de la República consideró que el nuevo consejo sólo debería coordinar las iniciativas del Ejecutivo y estar bajo el control de los ministros y la experiencia de los políticos profesionales $^{91}$. Asimismo, si la CPC consideró que la experiencia 
práctica de los hombres de empresa eran condición suficiente para dirigir las políticas económicas y productivas del país a través del Consejo, Alessandri los incluyó, pero, restándoles toda posibilidad de gobernar autónomamente la recién creada institución.

La respuesta de las asociaciones empresariales no tardó en llegar. En un extenso memorial la CPC lamentó que los representantes de las fuerzas productoras fueran considerados tan sólo como “... asesores, reservando a cuatro ministros de Estado las atribuciones del Consejo propiamente tal'. En esta controversia, los representantes Conservadores y Liberales se mantuvieron al margen, tomando caminos diferentes a los que proponían las fuerzas empresariales agrupadas en la multigremial. En este caso, y como en otros futuros momentos, las redes horizontales entre los hombres de negocio y los partidos políticos de derecha resultaron débiles.

A pesar de la opinión de la CPC, SOFOFA terminó adoptando una posición claramente más adaptativa a las condiciones políticoinstitucionales que se consolidaban en los años treinta. Utilizando las páginas de la revista gremial Boletín, los industriales destacaron que en definitiva "...lo importante es que haya un organismo que pueda coordinar las diferentes iniciativas gubernativas" 92 .

\section{Reflexiones Finales}

Las dificultades económicas y sociales a partir de 1931, y la crisis política estructural, terminaron con las tradicionales formas de relaciones entre las asociaciones empresariales y los poderes públicos. En un cuadro social y político adverso las asociaciones patronales pusieron énfasis en la rearticulación y consolidación de sus organizaciones $y$, por otra parte, colaboraron con el intervencionismo y los diferentes ensayos de fomento productivo estatal de la primera mitad de los años treinta. En esta coyuntura difícil, SOFOFA asumió crecientemente un liderazgo gremial que la posicionó como la asociación empresarial más activa en defensa de los intereses de los empresarios nacionales, elaborando propuestas, demandas y observaciones a las políticas de desarrollo económico que emanaban de las agencias de desarrollo económico estatal. 
La renovación organizacional de las fuerzas de la producción en su conjunto culminó en la decisión de unir fuerzas en defensa de sus intereses y hacer frente al cuestionamiento de los pilares de la actividad privada mediante la organización de la CPC. Inicialmente, las aspiraciones empresariales fueron intervenir en el diseño de las políticas económicas del país y para esto la iniciativa del Consejo Económico resultaba fundamental. Si la multigremial abogó por un Consejo de carácter técnico, Alessandri terminó imponiendo el rol articulador de la clase política profesional. Se trató de una derrota para las asociaciones empresariales que posteriormente las políticas de fomento productivo y el proyecto CORFO ayudaron en parte a olvidar.

En adelante, el camino de las asociaciones empresariales fue afinar los repertorios de acción política para posicionar las demandas y peticiones empresariales frente a la clase política civil. Ese camino es el que liderará la SOFOFA en la década de 1940. Paradojalmente, la derrota sufrida por la CPC en la disputa por el control de las políticas productivas a través del Consejo Económico fue infringida por el progenitor de quien asumiría desde 1947 la más larga conducción de la multigremial: Jorge Alessandri Rodríguez.

BiBLIOGRAFÍA

ARRIAGADA, Genaro. Los empresarios y la politica, Santiago, LOM Ediciones, 2004.

La oligarquía patronal chilena, Santiago, Nueva Universidad, 1970.

BELINI, Claudio, Historia de la industria en la argentina: De la independencia a la crisis del 2001, Buenos Aires, Editorial Sudamericana, 2017.

BURBACH, Roger, The Chilean industrial bourgeoisies and foreing capital, 1920 - 1970, Indiana University, 1975.

CAVAROZZI, Marcelo. The government and the industrial bourgeosie in Chile: 1938 - 1964. University of California, 1975.

CEPPI MAYOL DE LUPE, Sergio et all, Chile 100 años de industria 
(1883 - 1983), Santiago, Editado por SOFOFA, 1983.

CORREA, Sofía. Con las riendas del poder. La derecha chilena en el siglo XX, Santiago, Random House Mondadori S.A., 2011.

CHARLÍN O., Carlos. Del avión rojo a la república socialista, Santiago, Editorial Quimantú, 1972

DE RAMÓN, Armando, Biografía de chilenos: miembros de los poderes ejecutivo, legislativo y judicial (1876 - 1973), Santiago, Ediciones Universidad Católica de Chile, 1999

DÍAZ, José; Lüders, Rolf y Wagner, Gert, Chile 1810 - 2010. La República en cifras. Historical Statistics. Ediciones Universidad Católica de Chile, Santiago, 2016.

DINAMARCA, Manuel, La República socialista chilena: orígenes legitimos del Partido Socialista, Santiago, Ediciones Documentas, 1987

DRAKE, Paul, Socialismo y populismo. Chile, 1936-173, Valparaíso, serie monografías históricas 6, 1992.

ELLSWORTH, P. T., Chile: An Economy in Transition, Greenwood Press, 1945, pp. $51-61$;

DÍAZ, José; Lüders Rolf y Wagner, Gert, La República en cifras. Historical Statistics. Ediciones Universidad Católica de Chile. Santiago, 2016.

DONOSO, Ricardo, Alessandri, agitador y demoledor. Cincuenta años de historia política chilena, Volumen II, Santiago, Colección Tierra Firme, Fondo de Cultura Económica, 1954.

FERMANDOIS, Joaquín, Abismo y cimiento. Gustavo Ross y las relaciones entre Chile y Estados Unidos, 1932-1938, Santiago de Chile, Ediciones Universidad Católica de Chile, 1997.

FISCHER, Karin, Clase dominante y desarrollo desigual. Chile entre 1830 y 2010, Santiago, Ediciones Universidad Alberto Hurtado, 2017.

GÓNGORA, Mario, "Libertad política y concepto económico de gobierno en Chile hacia 1915 - 1935”, Estudios Históricos 8, Santiago, 1986.

JOBET, Julio César, Elpartido socialista de Chile, Santiago, Ediciones prensa latinoamericana S. A., 1971 
MENGES, Constantine, "Public policy and organized business in Chile”, Journal of International Affairs, XX, 1966

MONTERO, Cecilia. La revolución empresarial chilena, Cieplan/ Dolmen Ediciones, Santiago de Chile, 1997.

MOULIAN, Tomás. Fracturas. De pedro Aguirre Cerda a Salvador Allende (1938-1973), Santiago, LOM Ediciones, 2014.

NAZER AHUMADA, Ricardo, "Renovación de las élites empresariales en Chile". En Ossandon, José y Tironi, Eugenio. Adaptación. La empresa chilena después de Friedman, Santiago, Ediciones Universidad Diego Portales, 2013

SALAZAR, Gabriel, La enervante levedad histórica de la clase politica civil (Chile, 1900 - 1973), Santiago, Penguin Random House Grupo Editorial, 2015.

SALAZAR, Gabriel y Pinto, Julio. Historia contemporánea de Chile I. Estado, legitimidad, ciudadania, Santiago, LOM Ediciones, 1999.

SCHNEIDER, Ben Ross, Business Politics and the State in TwentiethCentury Latin America, Cambridge, Cambridge University Pres, 2004.

VALDIVIA, Verónica, El nacionalismo chileno en los años del Frente Popular (1938 - 1952), Santiago, Universidad Católica Blas Cañas, serie de investigaciones 3, 1995.

VARGAS, Juan Eduardo, La Sociedad de Fomento Fabril, 1883 1928, Santiago, Imprenta Universidad Católica, 1976.

\section{Fuentes}

Actas de las Sesiones del Consejo Directivo de la Sociedad de Fomento Fabril, 1928-1935.

Boletín, revista de la Sociedad de Fomento Fabril, 1928 - 1935 El Mercurio, 1928 - 1935.

Memoria Corporativa Confederación de la Producción y el Comercio, $2015-2017$. 


\section{Notas de PÁGina}

${ }^{1}$ Schneider, Ben Ross, Business Politics and the State in TwentiethCentury Latin America, Cambridge, Cambridge University Pres, 2004, p. 11.

${ }^{2}$ Arriagada, Genaro, Los empresarios y la politica, Santiago, LOM Ediciones, 2004, p. 95.

3 Hacemos nuestro la descripción sobre dislocación entre lo social y el régimen político durante los años 1931 - 1932 que propone Marcelo Cavarozzi. Ver Cavarozzi, Marcelo, Los sótanos de la democracia chilena, 1938 - 1964. Las esferas de <<protección>> de los empresarios industriales: la Corfo, represión a los obreros y la inflación, Santiago, LOM Ediciones, 2017, p. 35.

${ }^{4}$ Cavarozzi, Marcelo. op. cit., p. 248; Montero, Cecilia, La revolución empresarial chilena, Cieplan/Dolmen Ediciones, Santiago, 1997. pp. $97-98$.

${ }^{5}$ Cavarozzi, Marcelo, op. cit.; Correa Sutil, Sofía, Con las riendas del poder. La derecha chilena en el siglo XX, Santiago, Sudamericana, 2005; Arriagada, Genaro, Los empresarios... op. cit., y López, Eduardo, Los gremios empresariales y el Estado: Chile y Argentina, 1938 - 1955, Tesis Doctoral 2017.

${ }^{6}$ Correa Sutil, Sofía, op. cit., pp. $39-40$.

${ }^{7}$ Ellsworth, P. T., Chile: An Economy in Transition, Greenwood Press, 1945, pp. 51 - 61; Díaz, José; Lüders Rolf y Wagner, Gert, La República en cifras. Historical Statistics. Ediciones Universidad Católica de Chile. Santiago, 2016, p. 374.

${ }^{8}$ Arriagada, Genaro, Los empresarios... op. cit., p. 95.

9 Drake, Paul, Socialismo y populismo. Chile, 1936 - 173, Valparaíso, serie monografías históricas 6, 1992, pp. 166 - 167.

${ }^{10}$ Correa Sutil, Sofía, op. cit., pp. 40 - 41; Montero, Cecilia, op. cit., p. 91; Cavarozzi, Marcelo, op. cit.,

${ }^{11}$ Arriagada, Genaro, Los empresarios... op. cit., p. 96.

${ }^{12}$ Ceppi Mayol de Lupe, Sergio et all, Chile 100 años de industria (1883 - 1983), Santiago, Editado por SOFOFA, 1983.

13 Salazar, Gabriel, La enervante levedad histórica de la clase politica civil (Chile, 1900 - 1973), Santiago, Penguin Random House Grupo Editorial, 2015, pp. 373 - 374. 
14 Ver Fischer, Karin, Clase dominante y desarrollo desigual. Chile entre 1830 y 2010, Santiago, Ediciones Universidad Alberto Hurtado, 2017, pp. 91 - 92; Arriagada, Genaro, La oligarquía patronal chilena, Santiago, Nueva Universidad, 1970; Burbach, Roger, The Chilean industrial bourgeoisies and foreing capital, 19201970, Indiana University, 1975.

${ }^{15}$ Menges, Constantine, "Public policy and organized business in Chile", Journal of International Affairs, XX, 1966, p. 351 - 351. ${ }^{16}$ Correa Sutil, Sofía, op. cit., pp. 38 - 39.

${ }_{17}$ Vargas, Juan Eduardo, La Sociedad de Fomento Fabril, 1883 1928, Santiago, Imprenta Universidad Católica, 1976, pp. 47 - 48.

${ }^{18}$ Francisco Antonio Encina Armanet (1874 - 1965). Se tituló de abogado en la Escuela de Derecho de la Universidad de Chile en 1896. Ingreso al Partido Nacional y fue electo diputado por Linares, Parral y Loncomilla en el período 1906-1909. El año 1912 publicó uno de sus ensayos nacionalistas más importantes: "Nuestra Inferioridad Económica”. Fue consejero de la Sociedad Nacional de Agricultura (SNA) y de la Sociedad de Fomento Fabril (SOFOFA). Es uno de los historiadores más polémicos de nuestra historiografía. Calificado de falsificador y plagiario, su monumental Historia de Chile se constituyó en un éxito de ventas, obteniendo el Premio Nacional de Literatura en 1955. https:/www.bcn.cl/historiapolitica/ resenas_parlamentarias/wiki/Francisco_Antonio_Encina_Armanet. Visitado el 17 de agosto 2017.

${ }^{19}$ Ramón Guillermo Subercaseaux Pérez (1872 - 1959). Hizo sus estudios de humanidades en el Colegio San Ignacio y el Instituto Nacional. Diputado por Chillán y San Carlos, en el periodo 19091912. Reelecto diputado en el periodo $1912-1915$ y 1915-1918. En 1924 fue elegido senador por Nuble en el periodo 1924-1930. En 1907 fue ministro de Hacienda del gobierno del presidente Montt. En el año 1915, junto con Edwards y Encina, fue cofundador del partido Unión Nacionalista, en representación del cual se presentó candidato a senador ese mismo año, sin éxito. Fue director de la Sociedad Explotadora de Tierra del Fuego; uno de los creadores del Banco Central y presidente en 1933. Miembro de la Alta Co- 
misión Financiera Panamericana y del Instituto de Ingenieros de Chile. Fue miembro honorario de la Sociedad de Fomento Fabril y socio del Club de La Unión. https://www.bcn.cl/historiapolitica/ resenas_parlamentarias/wiki/Ram\%C3\%B3n_Guillermo_del_Carmen_Subercaseaux_P\%C3\%A9rez. Visitado el 17 de agosto 2017.

${ }^{20}$ Juan Pablo Bennett Argandońa (1871 - 1951). Oficial del Ejército de Chile. En 1909 fue nombrado agregado militar en la Embajada de Berlín y ministro de Guerra en 1924. El 11 de septiembre participó del Golpe de Estado contra el gobierno de Arturo Alessandri Palma. Miembro destacado de la Junta Militar de 1924 el 6 de febrero de 1925 fue retirado del servicio activo, ocupando posteriormente el cargo de director de la maestranza del Ejército.

${ }^{21}$ Góngora, Mario, "Libertad política y concepto económico de gobierno en Chile hacia 1915 - 1935”, Estudios Históricos 8, Santiago, 1986, p. 16.

${ }^{22}$ Walter Müller Hess, Ingeniero Civil titulado en 1917 en la Universidad de Chile, institución donde ejerció como profesor de la Facultad de Matemáticas y Ciencias Físicas. Ingresó a la SOFOFA en 1930 y en 1932 fue elegido vicepresidente, posteriormente asumió como presidente entre 1934 y 1955 . Durante su carrera gremial fue director de la SONAMI y miembro de la SNA, además de presidente del Instituto de Ingenieros de Chile e ingeniero jefe de la "compañía de Consumidores de Gas de Santiago". Industria, marzo de 1935, p. 139.

23 Sesión Consejo Directivo de la SOFOFA No 1.554 del 28.10.1931, en Boletín, octubre de 1931, p. 636.

${ }^{24}$ Luis Matte Larraín (1891 - 1936). Político e Ingeniero Civil. Junto a su hermano Arturo Matte, fue fundador de la Compañía Manufacturera de Papeles y Cartones (1920) y pionero de las plantaciones forestales en el fundo San Miguel en Chillán (1933). Fue ministro de Fomento y Agricultura durante el primer gobierno de Carlos Ibáñez del Campo. Ver De ramón, Armando, Biografía de chilenos: miembros de los poderes ejecutivo, legislativo y judicial (1876 - 1973), Santiago, Ediciones Universidad Católica de Chile, 1999, vol. 2, p. 110 
25 Sesión Consejo Directivo de la SOFOFA No 1.555 del 4.11.1931, en Boletín, noviembre de 1931, pp. 679- 680.

26 Sesión Consejo Directivo de la SOFOFA No 1.558 del 25.11.1931, en Boletín, noviembre de 1931, p. 685.

27 Sesión Consejo Directivo de la SOFOFA No 1.570 del 6.04.1932, en Boletín, abril de 1932, p. 194.

${ }^{28}$ Ibid.

${ }^{29}$ Carlos Aguirre Luco. Ingeniero Civil. Perteneció a la Dirección de Ferrocarriles y la Dirección de Obras Públicas. Presidente de la Fábrica de Paños de Tomé y presidente de la Fábrica de Papeles y Cartones. http://fotosycalles.blogspot.cl/2011/07/nombre-de-algunas-calles-de-nunoa.html. Visitado el 5 de octubre 2017.

30 Pablo Krassa Krohn (n. Viena - Austria, 1885; f. Santiago, 1975) Obtuvo el título de ingeniero químico en Viena, graduándose posteriormente de doctor en esa disciplina en la Universidad de Karlsruhe en 1909. Fue contratado por el gobierno en 1921 para hacerse cargo de las cátedras de Química Física, Electroquímica y Química Industrial. En 1943 los respectivos laboratorios asociados a estas cátedras fueron agrupados en el Instituto de Investigación de Materias Primas. Decano de la Facultad entre 1945 y 1948. Durante ese periodo se llevó a cabo la reforma de los estudios de ingeniería y se crearon las carreras de ingenieros industriales y electricistas. Fue incorporado como miembro académico de la Facultad en junio 1950, en reemplazo de Alejandro Bertrand Huillard. file://Users/ Eduardo/Downloads/miembros\%20academicos\%20de\%20la\%20 facultad\%20pdf.pdf. Visitado el 5 de octubre 2017.

31 Sesión Consejo Directivo de la SOFOFA No 1.570 del 6.04.1932, en Boletín, abril de 1932, p. 194.

32 Sesión Consejo Directivo de la SOFOFA No 1.571 del 13.04.1932, en Boletín, abril de 1932, p. 194.

33 Boletín, mayo de 1932, p. 213.

${ }^{34}$ Drake, Paul, op. cit., p. 53; Ellsworth, P. T., op. cit, pp. $6-29$.

35 Boletín, mayo de 1932, p. 214.

${ }^{36}$ Ibid.

${ }^{37}$ Ibid., p. 215. 
${ }^{38}$ Ibid., p. 219.

39 Boletín, enero de 1933, p. 1.

${ }^{40}$ La República Socialista se inició el 4 de junio de 1932 con el Golpe de Estado al presidente Juan esteban Montero y se extendió con la salida forzosa de Carlos Dávila el 13 de septiembre del mismo año. Para algunos historiadores, como Julio César Jobet, la República Socialista correspondió a la breve experiencia de 12 días bajo el mando del general en retiro Arturo Puga y la participación del comodoro del aire Marmaduke Grove. Para una revisión de la República Socialista y la crisis política de los ańos treinta ver Dinamarca, Manuel, La República socialista chilena: orígenes legitimos del Partido Socialista, Santiago, Ediciones Documentas, 1987; Charlín O., Carlos. Del avión rojo a la república socialista, Santiago, Editorial Quimantú, 1972; Jobet, Julio César, El partido socialista de Chile, Santiago, Ediciones prensa latinoamericana S. A., 1971, pp. 65 - 76; Drake, Paul, op. cit., pp. 55 - 65; Valdivia, Verónica, El nacionalismo chileno en los años del Frente Popular (1938 - 1952), Santiago, Universidad Católica Blas Cańas, serie de investigaciones 3, 1995 , p. 7.

41 Sesión Consejo Directivo de la SOFOFA No 1.579 del 14.06.1932, en Boletin, junio de 1932, p. 307.

${ }^{42}$ Ibid.,

${ }^{43}$ Boletin, junio de 1932 , p. 269.

${ }^{44}$ Comunicación al señor Ministro de Fomento con fecha 23 de junio de 1932. En "Informes y correspondencia de la Sociedad". Boletin, junio de 1932, p. 300.

45 Ibid.,

${ }^{46}$ Respuesta del señor Ministro de Fomento con fecha 30 de junio de 1932. En "Informes y correspondencia de la Sociedad", Ibid., p. 301.

47 Ibid., p. 302.

${ }^{48}$ Boletin, 30 de septiembre de 1932, p. 414.

49 Sesión Consejo Directivo de la SOFOFA No 1.589 del 31.08.1932, en Boletín, 6 de septiembre de 1932, p. 399.

${ }^{50}$ Drake, Paul, op. cit., p. 65. 
${ }^{51}$ Boletín, enero de 1933, p. 4. Memoria del Consejo Directivo de la Sociedad de Fomento Fabril a la 490 Junta General de Socios el 04.01.1933.

${ }^{52}$ Moulian, Tomás. Fracturas. De pedro Aguirre Cerda a Salvador Allende (1938-1973), Santiago, LOM Ediciones, 2014, p. 23.

53 Nazer Ahumada, Ricardo, "Renovación de las élites empresariales en Chile”. En Ossandon, José y Tironi, Eugenio. Adaptación. La empresa chilena después de Friedman, Santiago, Ediciones Universidad Diego Portales, 2013. p. 94. Ver, además, Fermandois, Joaquín, Abismo y cimiento. Gustavo Ross y las relaciones entre Chile y Estados Unidos, 1932-1938, Santiago de Chile, Ediciones Universidad Católica de Chile, 1997, pp. 81 - 88.

${ }^{54}$ Cavarozzi, Marcelo. op. cit., pp. 38 - 39.

55 Donoso, Ricardo, Alessandri, agitador y demoledor. Cincuenta años de historia politica chilena, Volumen II, Santiago, Colección Tierra Firme, Fondo de Cultura Económica, 1954. p. 119

${ }^{56}$ Arriagada, Genaro, Los empresarios... op. cit., p. 95.

57 Sesión Consejo Directivo de la SOFOFA No 1.595 del 26.10.1932, en Boletin, octubre de 1932, p. 484.

58 Sesión Consejo Directivo de la SOFOFA No 1.594 del 19.10.1932, en Boletin, octubre de 1932, p. 484.

${ }^{59}$ El Mercurio, 21.08.1935, p. 13.

${ }^{60}$ Nazer Ahumada, Ricardo, op. cit., p. 94.

61 Sesión Consejo Directivo de la SOFOFA No 1.604 del 4.01.1933, en Boletín, enero de 1933, p. 53.

62 Sesión Consejo Directivo de la SOFOFA No 1.606 del 2.03.1933, en Boletin, marzo de 1933, p. 155.

63 Sesión Consejo Directivo de la SOFOFA No 1.608 del 10.03.1933, en Boletín, marzo de 1933, p. 157.

${ }^{64}$ Boletín, enero de 1934, p. 3. Memoria del Consejo Directivo de la Sociedad de Fomento Fabril a la 50 Junta General de Socios el 03.01.1934.

${ }^{65}$ Ibid., p, 156.

66 Sesión Consejo Directivo de la SOFOFA No 1.607 del 8.03.1933, en Boletín, marzo de 1933, p. 156. 
${ }^{67}$ La SNA y la SOFOFA tenían representantes conjuntos en el Banco Central, en las agencias estatales de crédito y fomento. Ver Menges, Constantine, op. cit., pp. $343-365$.

${ }^{68}$ Boletín, octubre de 1933, p. 504.

69 Sesión Consejo Directivo de la SOFOFA No 1.644 del 22.11.1933, en Boletín, noviembre de 1933, p. 590. Efectivamente, la Unión Industrial Argentina contaba con una lujosa sede en la Avenida de Mayo, a una distancia equidistante entre la Casa Rosada y el Parlamento, donde funcionaría hasta 1974. Ver Belini, Claudio, Historia de la industria en la argentina: De la independencia a la crisis del 2001, Buenos Aires, Editorial Sudamericana, 2017.

70 Sesión Consejo Directivo de la SOFOFA No 1.644 del 22.11.1933, en Boletín, noviembre de 1933, p. 591.

${ }^{71}$ Boletin, abril de 1934, pp. $172-172$.

72 Boletin, junio de 1934, p. 296.

73 Jaime Larraín García-Moreno (1896 - 1975). Abogado, agrónomo y político. Presidente del Partido Agrario entre 1946 y 1951. Electo diputado por "Valparaíso y Casablanca", en representación de la línea Conservadora de inspiración socialcristiana, en el período 1921-1924. En 1925 fue elegido consejero de la Sociedad Nacional de Agricultura y el 21 de abril de 1930 asumió como vicepresidente. El 3 de julio de 1933 fue ungido presidente, cargo que ocupó hasta diciembre de 1940. Senador por la Octava Agrupación Provincial "Biobío, Malleco y Cautín" en el período 1941-1949 y reelecto para el período 1949-1957. Precandidato a la presidencia de la República en 1946, apoyado por el Partido Agrario. Fundador y primer presidente de la Confederación de la Producción y del Comercio en 1934 hasta 1935.https://www.bcn.cl/historiapolitica/resenas_parlamentarias/wiki/Jaime Larra\%C3\%ADn Garc\%C3\%ADa Moreno. Visitado el 20 de octubre 2017.

${ }^{74}$ Boletin, junio de 1934 , p. 315.

${ }^{75}$ Boletín, julio de 1934, pp. 371 - 372. Ver, además, El Mercurio, 7.07.1934, p. 17 y la Memoria Corporativa Confederación de la Producción y el Comercio, 2015 - 2017, p. 13.

${ }^{76}$ Ibid., 
77 Boletín, junio de 1934, p. 297.

${ }^{78}$ Boletín, junio de 1934, p. 297.

${ }^{79}$ Ibid., p. 298. Ver Salazar, Gabriel y Pinto, Julio. Historia contemporánea de Chile I. Estado, legitimidad, ciudadania, Santiago, LOM Ediciones, 1999, p. 51.

${ }^{80}$ Menges, Constantine, op. cit., pp. 353.

${ }^{81}$ Salazar, Gabriel, La enervante levedad... op. cit., p. 383.

${ }^{82}$ Boletín, junio de 1934, pp. 318 - 322. "Conclusiones aprobadas por la Convención Gremial de la Producción y del Comercio".

${ }^{83}$ Ibid., p. 319.

${ }^{84}$ El Mercurio, 5.05.1935, "El corporativismo, válvula regulatoria del parlamentarismo en el futuro", p. 13.

${ }^{85}$ Boletín, julio de 1934, "Consejo Nacional de Economía. Proyecto de creación que presenta la Confederación de la Producción y del Comercio", pp. $373-374$.

${ }^{86}$ El Mercurio, 15.08.1934, "Que los gastos fiscales tengan un tope piden los productores y comerciantes confederados", p. 17.

${ }^{87}$ El Mercurio, 16.08.1934, "La política económica del Gobierno es sólo la del interés nacional”, p. 18.

${ }^{88}$ Boletín, agosto de 1934, p. 440.

${ }^{89}$ Boletín, noviembre de 1934, p. 651; Diario Oficial 5.11.1934.

${ }^{90}$ Entre los representantes de las fuerzas productoras se encontraban uno de la Sociedad Nacional de Agricultura, otro de la Sociedad de Fomento Fabril, otro de la Sociedad Nacional de Minería, otro de la Corporación de Ventas del Salitre y del Yodo y otro de las Sociedades Agrícolas del Sur; en total cinco. El comercio cuenta con dos delegados de las Cámaras de Comercio mayoristas, dos de los minoristas, uno de los transportes y dos de las Bolsas de Comercio; en total siete. Las instituciones de crédito tienen tres delegados: uno del Banco Central, otro de la Caja de Crédito Hipotecario y otro de la Caja Nacional de Ahorros. Y los servicios públicos del Estado cuentan con tres funcionarios: el Superintendente de Bancos, el de Sociedades Anónimas y el director de los Ferrocarriles.

${ }^{91}$ Salazar, Gabriel, La enervante levedad... op. cit., p. 392.

92 Boletín, noviembre de 1934, p. 609. "Consejo de Economía 
Nacional”.

Fecha de Recepción del Artículo: 12 de septiembre de 2018 Fecha de Aceptación: 24 de octubre de 2018 